\title{
Fine structural evidence for hormone secretion by a human thymic tumour
}

\author{
R. F. MACADAM AND J. M. VETTERS \\ From the University Department of Pathology, Western Infirmary, Glasgow
}

SYNOPSIS An epidermoid type of thymoma from an asymptomatic 39-year-old male subject is described. Electron microscopy demonstrated endocrine type secretory granules within the tumour cells, and a minority of these granules resembled normal human pancreatic alpha cell granules. Fine structural evidence for endocrine secretory activity in a primary thymic tumour has not been previously described.

There are few fine structural reports of primary thymic tumours in man and to our knowledge these do not include certain features of the case described here.

CASE HISTORY

This thymic tumour came from a 39-year-old machine operator who was found, on mass miniature radiography, to have a tumour protruding into the right hemithorax from the upper mediastinum. A chest radiograph two years previously had been normal. The patient was symptom free and no haematological or endocrinological abnormalities were noted. At operation a discrete, pendunculated, pale pink, uniformly potatolike tumour $(100 \mathrm{~g})$ was removed completely from the anterosuperior mediastinum. Postoperative recovery was uneventful.

\section{MATERIALS AND METHODS}

Tissue for light microscopy was fixed sequentially in $10 \%$ formol saline and corrosive formalin, embedded in paraffin wax, and stained with haematoxylin and eosin and a variety of other stains. Tissue for electron microscopy was fixed in $2 \%$ phosphate-buffered glutaraldehyde, postosmicated, embedded in araldite, and stained with uranyl acetate and lead citrate.

\section{RESULTS}

The lesion was of the differentiated epidermoid type of thymic tumour (Thomson and Thackray, 1957) and was composed of trabeculae of large, pale staining, well differentiated epithelial cells with random occasional lymphocyte clumps (Fig. 1). The appearance was reminiscent of a tumour of endocrine origin. In addition, focal granulomata and areas of acinar formation were noted (Fig. 2). Non-neoplastic thymic tissue was present in the tumour pedicle base.

Received for publication 17 October 1968.
Electron microscopy confirmed the solid, epitheliallike nature of the tumour and desmosomes were present. All cells contained ribosome-studded endoplasmic reticulum and prominent Golgi complexes. Most cells contained large numbers of endocrine type secretory granules. Most of these were composed of dense homogeneous spherical cores centrally placed within vesicles of single unit membrane type. These granules measured on average $126 \mathrm{~m} \mu$ (Fig. 3). A minority of secretory granules were composed of a dense core in an eccentric position within the vesicle, the remainder of the vesicle space being filled with a crescent of less dense material (Fig. 4).

\section{DISCUSSION}

Endocrine type secretory granules have not previously been described in primary thymic tumours. Secretory granules, similar to the minority with crescents, have recently been described as the normal secretory product of the alpha cell of the human pancreatic islet (Like, 1967; Macadam, 1968). Secretory granules, consisting of eccentric cores and without less dense crescents, are found in normal rat adrenal medulla (Coupland, 1965), normal and neoplastic human adrenal medulla (Macadam, 1967), and occasionally within human small bowel carcinoid (Macadam, 1967). Pansky and House (1965), in a light microscopic study of the thymus of the AKR/JAX mouse, demonstrated a tinctorial similarity between some of the thymic cells and the beta cells of the pancreatic islet. Although no endocrinological upset was demonstrated in this 


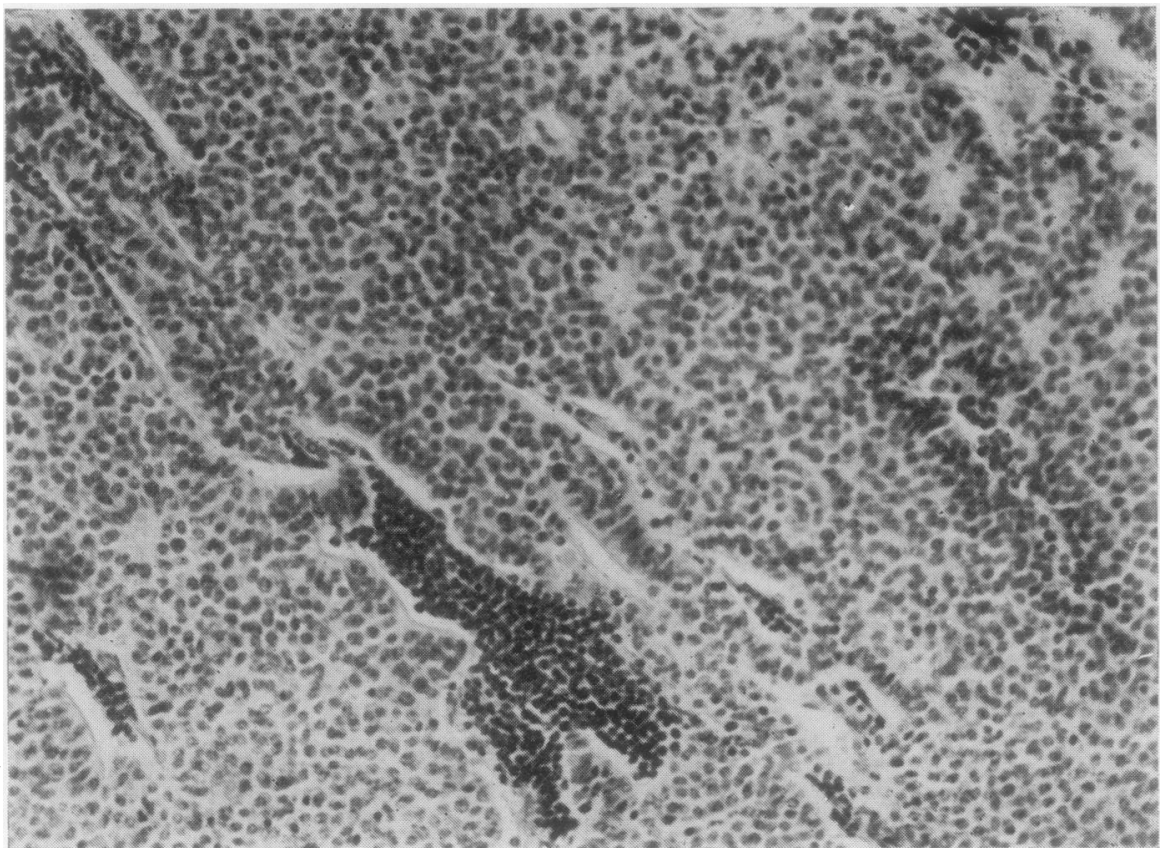

FIG. 1 Light
micrograph. Note the extensive masses of epithelig tumour cells and occasional

lymphocyte clump $\vec{\odot}$ Haematoxylin and eosin $\times 210$.

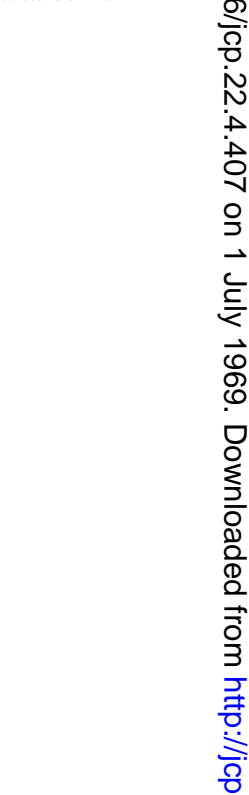

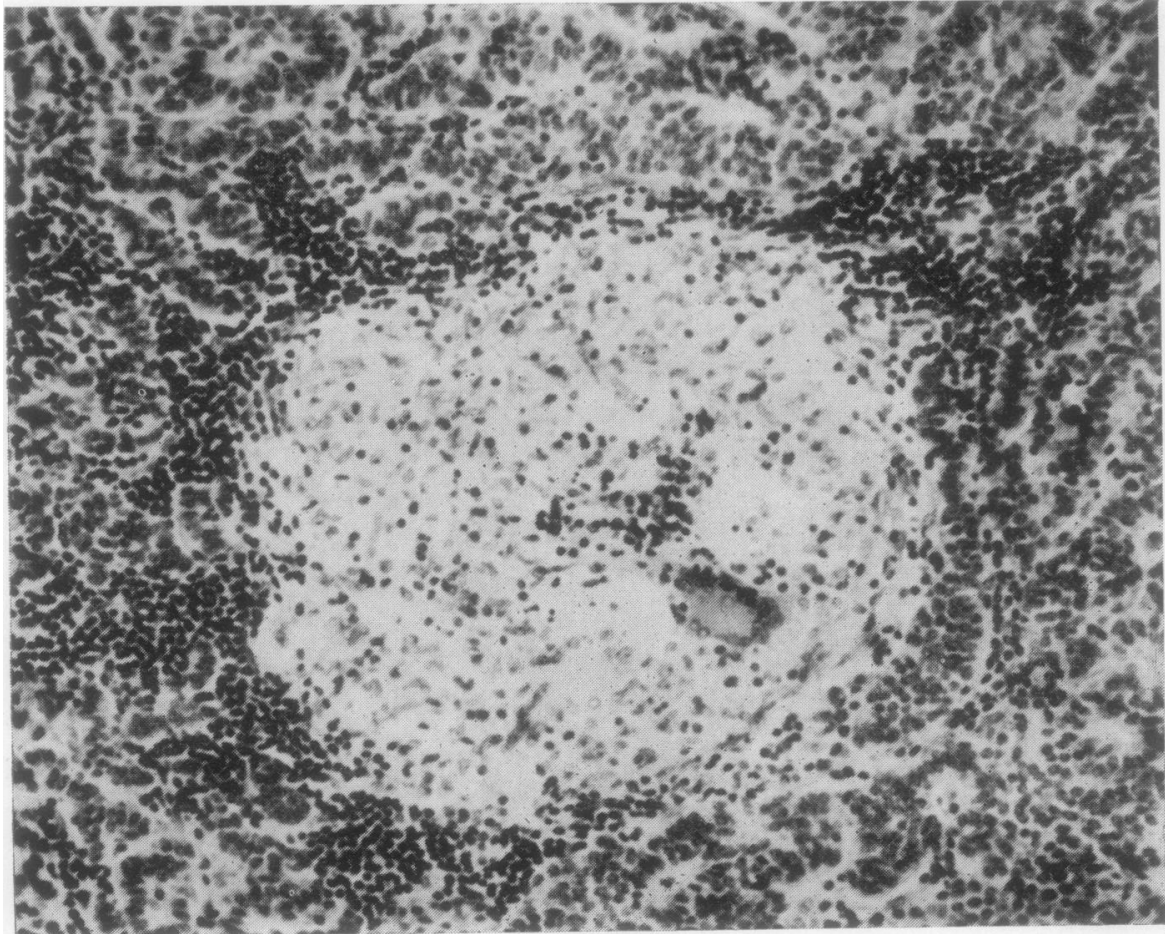

FIG. 2 Light micrograph. Note the central granuloma and the peripheral attempts at acinar? formation. Haematoxylin and eosin $\times 525 . N$ 


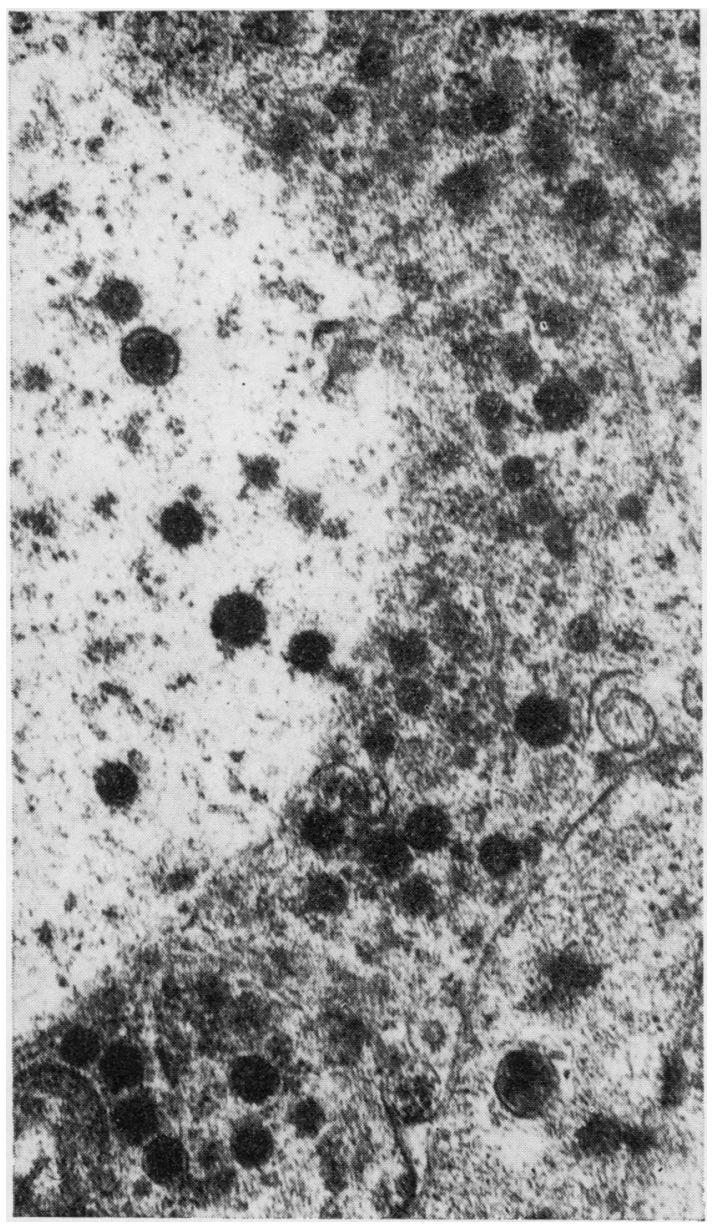

FIG. 3.

case, the fine structural findings give weight to previous reports of abnormal endocrinological activity in patients with thymic tumours (Azzopardi, 1966).

Our thanks are due to $\mathrm{Mr} \mathbf{K}$. Fraser for permission to use the surgical material in this case.

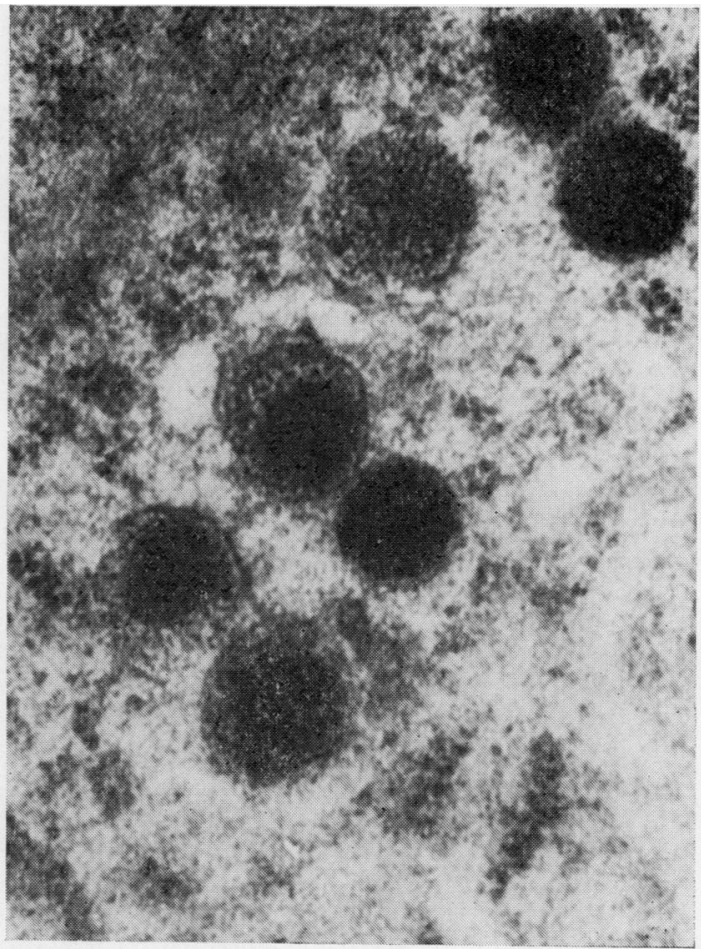

FIG. 4.

FIG. 3 Electron micrograph. Adjacent tumour cells contain multiple secretory granules $(\times 50,000)$.

FIG. 4 Electron micrograph. Seven secretory granules are illustrated, two of which are composed of a dense eccentric core and a less dense crescent $(\times 70,000)$.

\section{REFERENCES}

Azzopardi, J. G. (1966). In Recent Advances in Pathology, edited by C. V. Harrison, 8th ed., p. 98. Churchill, London.

Coupland, R. E. (1965). J. Anat., (Lond.) 99, 231.

Like, A. A. (1967). Lab. Invest., 16, 937.

Macadam, R. F. (1967). Unpublished results.

- (1968). Unpublished results.

Pansky, B., and House, E. L. (1965). Anat. Rec., 152, 451.

Thomson, A. D., and Thackray, A. C. (1957). Brit. J. Cancer, 11, 348. 